\title{
Decreased Staphylococcus aureus and increased osteoblast density on nanostructured electrophoretic-deposited hydroxyapatite on titanium without the use of pharmaceuticals
}

\author{
This article was published in the following Dove Press journal: \\ International Journal of Nanomedicine \\ 8 April 2014 \\ Number of times this article has been viewed
}

\author{
Dennis Mathew' \\ Garima Bhardwaj',2 \\ Qi Wang ${ }^{3}$ \\ Linlin Sun ${ }^{3}$ \\ Batur Ercan ${ }^{3}$ \\ Manisavagam Geetha' \\ Thomas J Webster ${ }^{3,4}$ \\ 'Department of Biomedical \\ Engineering, VIT University, Vellore, \\ Tamil Nadu, India; ${ }^{2}$ Centre for \\ Biomaterials Science and Technology \\ School of Mechanical and Building \\ Sciences, VIT University, Vellore, \\ Tamil Nadu, India; ${ }^{3}$ Department of \\ Chemical Engineering and Program \\ in Bioengineering, Northeastern \\ University, Boston, MA, USA; \\ ${ }^{4}$ Center of Excellence for Advanced \\ Materials Research, University of King \\ Abdulaziz, Jeddah, Saudi Arabia
}

Correspondence: Thomas J Webster Department of Chemical Engineering, Northeastern University, Boston, MA 02II5, USA

Tel +l 6173736585

Email th.webster@neu.edu
Background: Plasma-spray deposition of hydroxyapatite on titanium (Ti) has proven to be a suboptimal solution to improve orthopedic-implant success rates, as demonstrated by the increasing number of orthopedic revision surgeries due to infection, implant loosening, and a myriad of other reasons. This could be in part due to the high heat involved during plasma-spray deposition, which significantly increases hydroxyapatite crystal growth into the nonbiologically inspired micron regime. There has been a push to create nanotopographies on implant surfaces to mimic the physiological nanostructure of native bone and, thus, improve osteoblast (bone-forming cell) functions and inhibit bacteria functions. Among the several techniques that have been adopted to develop nanocoatings, electrophoretic deposition (EPD) is an attractive, versatile, and effective material-processing technique.

Objective: The in vitro study reported here aimed to determine for the first time bacteria responses to hydroxyapatite coated on Ti via EPD.

Results: There were six and three times more osteoblasts on the electrophoretic-deposited hydroxyapatite on Ti compared with $\mathrm{Ti}$ (control) and plasma-spray-deposited hydroxyapatite on Ti after 5 days of culture, respectively. Impressively, there were 2.9 and 31.7 times less Staphylococcus aureus on electrophoretic-deposited hydroxyapatite on Ti compared with Ti (control) and plasma-spray-deposited hydroxyapatite on Ti after 18 hours of culture, respectively. Conclusion: Compared with uncoated $\mathrm{Ti}$ and plasma-sprayed hydroxyapatite coated on $\mathrm{Ti}$, the results provided significant promise for the use of EPD to improve bone-cell density and be used as an antibacterial coating without resorting to the use of antibiotics.

Keywords: bacteria, nanotechnology, electrophoretic deposition, inhibition

\section{Introduction}

Titanium (Ti) is one of the most widely used implant materials due to its superior specific strength, light weight, and corrosion resistance as a result of the formation of a protective titanium dioxide $\left(\mathrm{TiO}_{2}\right.$ ) layer. ${ }^{1}$ However, to improve juxtaposed bone growth on Ti implants, sometimes hydroxyapatite (HA; a chemical analog to the inorganic phase of bone) is coated on Ti surfaces via a plasma-spray-deposition technique. ${ }^{1}$ Unfortunately, this has proven to be a suboptimal solution to improve orthopedicimplant success rates, since the number of total hip revision surgeries is on the rise, with over 40,000 revision surgeries per year in the USA.,3 Such numbers will only rise, since, in 2009, the number of total hip replacement procedures was 327,000 , three times the total number of hip replacement surgeries in $1991 .^{2}$ The reason why 
plasma spraying of HA has proven to be suboptimal could be in part due to the high heat involved during plasma-spray deposition, which significantly increases HA crystal growth into the nonbiologically inspired micron regime.

Parallel to the increase in implant insertions per year, the number of revision surgeries has also increased for a variety of reasons including infection and implant loosening due to bone necrosis, which occurs in the presence of wear debris. ${ }^{3}$ In particular, there is a corresponding increase in the number of orthopedic-device failures related to infection. ${ }^{3}$ Among the various causes, failure due to infection, also known as "septic failure," is the most common cause for revision surgeries in total knee arthroplasties (25\%), the third most common cause in all total hip arthroplasties (15\%), and the most common reason for the removal of all total knee arthroplasties and total hip arthroplasties (79\% and 74\%, respectively), while costing about US\$70,000 per episode. ${ }^{4-6}$ These statistics highlight the difficulty in treating orthopedic-implant and other medical-device infections using today's pharmaceutical approaches.

Currently, antibiotics are the only common therapy for treating medical-device-related infections. However, this treatment predominantly targets free-floating planktonic bacteria and does not effectively interrupt sessile bacteria formation in a biofilm. The efficacy of antibiotics toward treating bacterial infections is decreasing based on the rise of multiple antibiotic-resistant strains of bacteria including Staphylococcus aureus. ${ }^{7,8}$ Antibiotic-resistant strains of bacteria cannot be treated with the use of antibiotics once they adhere to the implant surface and often the device needs to be removed to successfully eradicate the infection. ${ }^{7,8}$ Orthopedic-device removal is both a painful and demanding multistep procedure that requires joint washout, bone debridement, and prolonged oral antibiotic therapy. ${ }^{9}$ With this in mind, there is a growing interest in finding alternative ways to treat orthopedic-device-related infections without the use of antibiotics. Some of the current options focus on altering the surface properties of Ti or HA in such a way that minimizes initial bacterial attachment. ${ }^{10}$

Along these lines, in recent years, there has been a push to create nanotopographies on implant surfaces to mimic the physiological nanostructure of native bone and, thus, improve osteoblast (bone-forming-cell) functions. ${ }^{11}$ For example, because of the ease of fabrication and its improved biocompatibility properties, anodizing $\mathrm{Ti}$ to possess nanotubular features has been shown to control stem cell-implant interactions, ${ }^{12,13}$ increase bone growth, ${ }^{14-17}$ decrease bacterial functions, ${ }^{18-20}$ improve bladder-stent urothelialization, ${ }^{21,22}$ improve skin growth, ${ }^{14,23}$ and reduce inflammation. ${ }^{14,24}$
However, little effort has been focused on creating nanoscale surface features on HA coatings on Ti to specifically reduce implant infections.

Among the several techniques that have been adopted to develop nanocoatings, electrophoretic deposition (EPD) is an attractive, versatile, and effective material-processing technique that can be used for biomedical applications. EPD produces highly homogenous coatings at a high deposition rate with an adequate control over deposition thickness. It can deposit thicker, denser, and more adherent coatings on wide range of shapes and three-dimensional complex porous structures. ${ }^{25}$ For example, Boccaccini et al portrayed in their work that EPD can be adopted for coating polystyrene beads with nano $\mathrm{TiO}_{2}$, resulting in a desirable nanotopography; such surfaces are highly relevant for biomedical applications, as the authors confirmed enhanced bone-cell adhesion and osseointegration on such implant surfaces. ${ }^{26}$ In addition, for post-processing of EPD coatings, sintering helps to densify the deposit and eliminate porosity. As compared with plasma spraying of HA and conventional dip-coating techniques, EPD provides superior uniformity for coating metals. ${ }^{25}$ EPD is carried out at lower temperatures and hence it eliminates the challenges faced due to high temperature processes during traditional glass-melting techniques, thus, exhibiting low thermal capability. ${ }^{27}$ Several authors ${ }^{28-31}$ have concluded that EPD employed for HA coatings exhibits strong interfacial bonding on Ti alloys and in vitro studies have also proved EPD to be a superior coating technique, as it provides higher bond strength than plasma-sprayed HA and chemically precipitated HA coatings. Further, EPD provides corrosion resistance to coatings, which has been reported to be 50-100 times higher than that provided by plasma spraying. ${ }^{10,28}$ Bioactive HA coatings formed via EPD exhibit a lower dissolution rate than conventional spraying techniques because of the retention of crystalline phases instead of amorphous phases as in the case of plasma spraying. ${ }^{10,29}$ Last, but not least, EPD is a costeffective technique that can implement nanostructures to improve implant performance. ${ }^{25}$

Despite the promise of EPD for coating HA on Ti for medical-device applications, to date, as far as we are aware, there have been few (if any) studies examining bacteria responses on such substrates.

Bearing all this in mind, the objective of the in vitro study reported here was to determine for the first time bacteria responses to HA coated on Ti via EPD. Compared with uncoated Ti and plasma-sprayed $\mathrm{HA}$ on $\mathrm{Ti}$, the results provide significant promise for the use of EPD to improve 
Table I Conditions for plasma-spray deposition of hydroxyapatite on titanium

\begin{tabular}{ll}
\hline Condition & Parameter \\
\hline Primary spray gas, $\mathrm{Ar}$ & $40 \mathrm{SLPM}$ \\
Secondary spray gas, $\mathrm{H}_{2}$ & $10 \mathrm{SLPM}$ \\
Carrier gas, Ar & $2 \mathrm{SLPM}$ \\
Powder-flow rate & $25 \mathrm{~g} / \mathrm{min}$ \\
Plasma-jet type & $\mathrm{F} 4-\mathrm{MB}$ \\
Injector size, diameter & $1.8 \mathrm{~mm}$ \\
Powder-feeding distance & $8 \mathrm{~mm}$ \\
Spray current & $650 \mathrm{~A}$ \\
Spray voltage & $58 \mathrm{~V}$ \\
Spray distance & $100 \mathrm{~mm}$ \\
\hline
\end{tabular}

Abbreviation: SLPM, standard liters per minute.

osteoblast density and as an antibacterial coating without resorting to the use of antibiotics.

\section{Materials and methods Materials}

All of the tests in this study were performed on a Ti alloy, Ti-6Al-4V (Alfa Aesar, Ward Hill, MA, USA), which was cut into $1 \times 1 \mathrm{~cm}$ small pieces. Nanophase $\mathrm{HA}$ was prepared by wet chemical synthesis using $\mathrm{Ca}\left(\mathrm{NO}_{3}\right)_{2} 4 \mathrm{H}_{2} \mathrm{O}, \mathrm{KH}_{2} \mathrm{PO}_{4}$, distilled water, ammonia, and acetone with a stirring time of 1 hour and an aging time of 24 hours, followed by filtering then sintering at $900^{\circ} \mathrm{C} .{ }^{25}$ The HA was then coated onto the alloy using EPD. ${ }^{28,30}$ For this, the electrolyte was prepared by dissolving HA in isopropyl alcohol, stirring for 10 minutes then allowing the mixture to settle overnight. Previous studies have demonstrated no change in crystallinity or chemistry using this procedure..$^{28,30}$ The mixture was again stirred for 2 hours before starting the coating and Ti-6Al-4V was used as the working electrode (-ve) and 316 stainless steel was used as a counter electrode (+ve). Voltage varying from 40 to $80 \mathrm{~V}$ was used for 2-5 minutes. Optimal coating was achieved at $60 \mathrm{~V}$ for 4 minutes. For comparison with a popular conventional HA coating technique, Ti-6Al-4V was plasma sprayed with micron-sized HA obtained from Himed (Old Bethpage, NY, USA), at the conditions and parameters listed in Table $1 .^{31}$ The micron-sized HA and processing parameters were
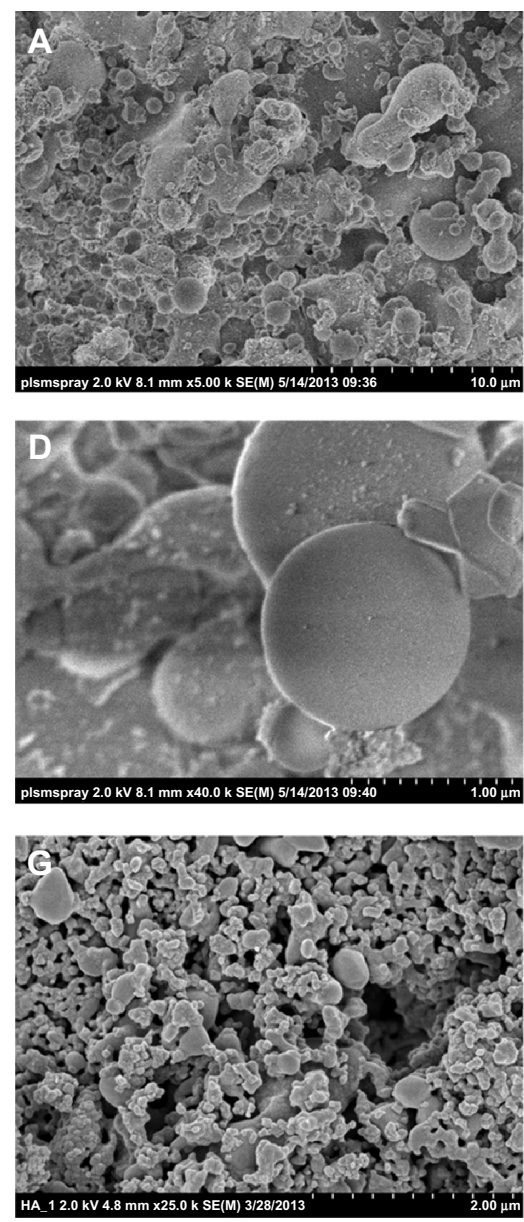
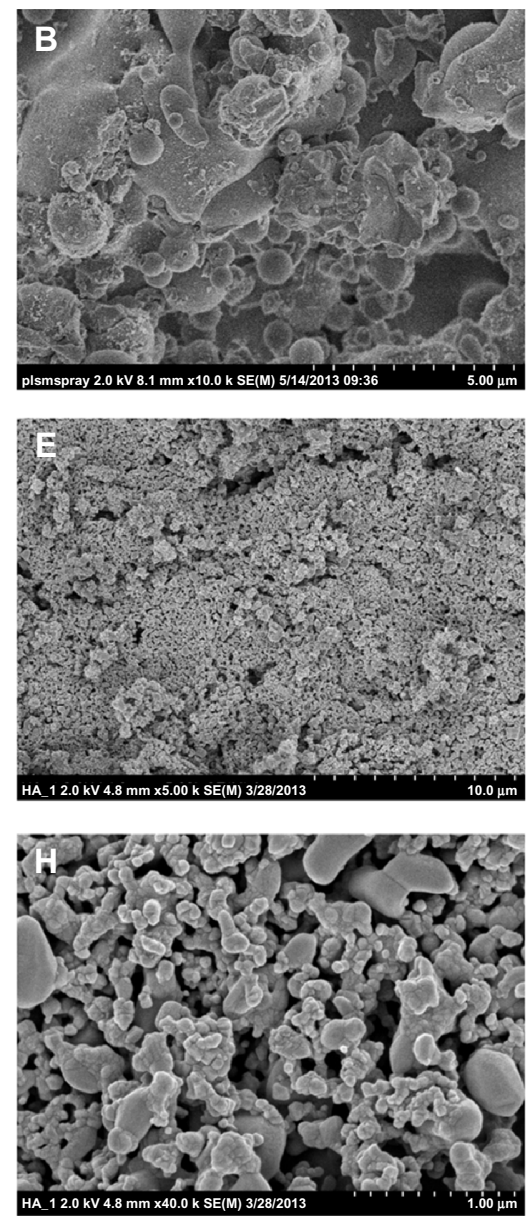
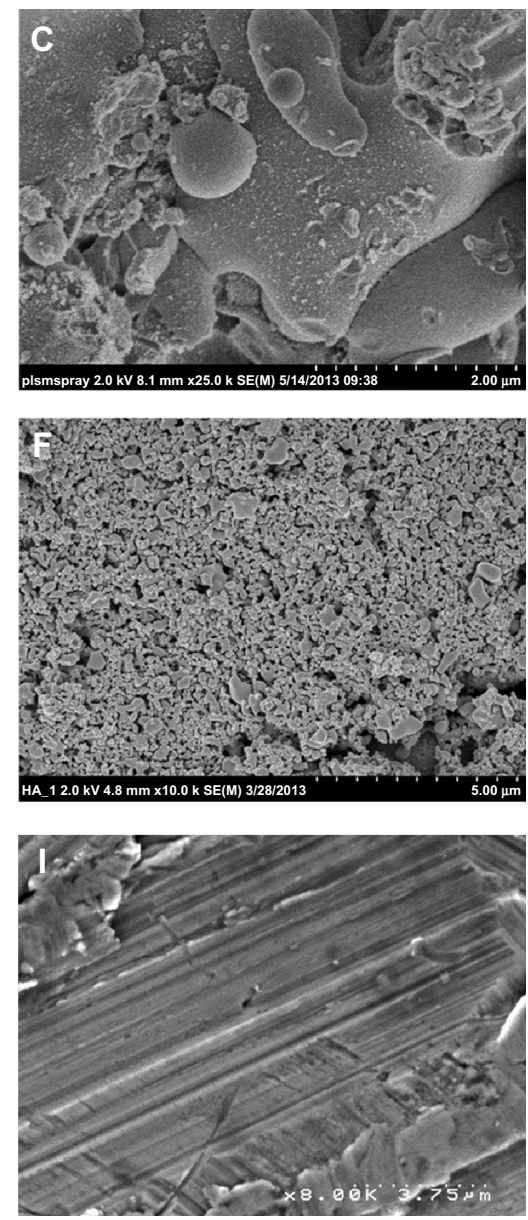

Figure I Scanning electron microscopy images of the samples of interest to the present study. It is clear that the electrophoretic-deposited (EPD) hydroxyapatite on titanium samples had the greatest degree of nanoscale surface roughness. (A-D) Plasma-sprayed hydroxyapatite on titanium. (E-H) EPD hydroxyapatite on titanium. (I) Plain titanium. 
chosen to best emulate current processes and materials used clinically today.

\section{Materials characterization}

Samples were characterized using scanning electron microscopy and contact angle analysis to confirm surface roughness and wettability of the coatings, all according to standard procedures. $^{31}$

\section{Osteoblast and bacteria experiments}

Osteoblasts purchased from ATCC (catalog number C12720, population number 1-3) were cultured in Dulbecco's Modified Eagle Medium supplemented with 10\% fetal bovine serum and $1 \%$ penicillin (HyClone; Thermo Fisher Scientific, Waltham, MA, USA). The samples were sterilized with $70 \%$ ethanol for 20 minutes then transferred into a 12-well plate and rinsed once with phosphate-buffered saline (PBS). A 4-hour 3-(4,5-dimethylthiazol-2-yl)-2,5-diphenyltetrazolium bromide (MTT) osteoblast adhesion assay (Sigma-Aldrich, St Louis, MO, USA; seeding density: 3,500 cells $/ \mathrm{cm}^{2}$ ) was performed to determine cell viability following the manufacturer's instructions. An MTT proliferation assay (seeding density: $3,500 \mathrm{cells} / \mathrm{cm}^{2}$ ) was performed after 1,3 , and 5 days of culture following the manufacturer's instructions. All experiments were conducted in triplicate and repeated three times each according to standard procedures. ${ }^{31}$

A bacterial assay was performed using $S$. aureus (American Type Culture Collection, Manassas, VA, USA). 0.03\% tryptic soy broth (TSB) and agar plates (Sigma-Aldrich) were used as the media. A small amount of $S$. aureus was taken from stock culture, streaked onto an agar plate, and then used as the stock plate for further experiments. Colonies were scraped off from the stock plate, added to $3 \mathrm{~mL}$ of $3 \%$ TSB and incubated at $37^{\circ} \mathrm{C}$ in humidified conditions under a $5 \%$ carbon dioxide atmosphere for 18 hours. A small amount $(0.1 \mathrm{~mL})$ of each sample was transferred to a few wells of a 96-well plate and absorption was measured at $562 \mathrm{~nm}$ using a plate reader. A value of 0.52 to 0.54 was obtained, indicating a density of $10^{9}$ bacteria $/ \mathrm{mL}$. A dilution of $10^{8}$ bacteria $/ \mathrm{mL}$ was then prepared using $0.03 \%$ TSB. The samples were sterilized with $70 \%$ ethanol for 20 minutes, transferred into a 12-well plate, and rinsed once with PBS. They were then treated with $2 \mathrm{~mL}$ of the $10^{8}$ bacteria/mL solution and incubated for 24 hours. The bacteria solution was removed and the samples were rinsed twice with PBS. They were transferred into $3 \mathrm{~mL}$ of PBS and sonicated for 10 minutes to create a first dilution $\left(10^{-1}\right)$ then three subsequent dilutions $\left(10^{-2}, 10^{-3}\right.$, and $\left.10^{-4}\right)$ were created. Following this, $0.1 \mathrm{~mL}$ of each of the $10^{-3}$ and $10^{-4}$ dilutions were plated and incubated for 18 hours. The number of bacterial colonies formed on each sample was counted and using these values, the number of bacteria $/ \mathrm{mL}$ was found.

All experiments were conducted in triplicate and differences between means were determined using analysis of variance followed by Student's $t$-tests.

\section{Results and discussion}

As expected, the results of the present study indicate that the electrophoretic-deposited HA on Ti possessed much greater nanoscale surface roughness than plasma-spray-deposited $\mathrm{HA}$ on Ti; both had greater nanoscale surface roughness compared with plain Ti (Figure 1). The increased surface wettability (or "hydrophilicity," as demonstrated via contact angle experiments) for the electrophoretic-deposited HA then followed due to the greater surface area and exposure of HA on Ti (Figure 2). Although requiring more investigation
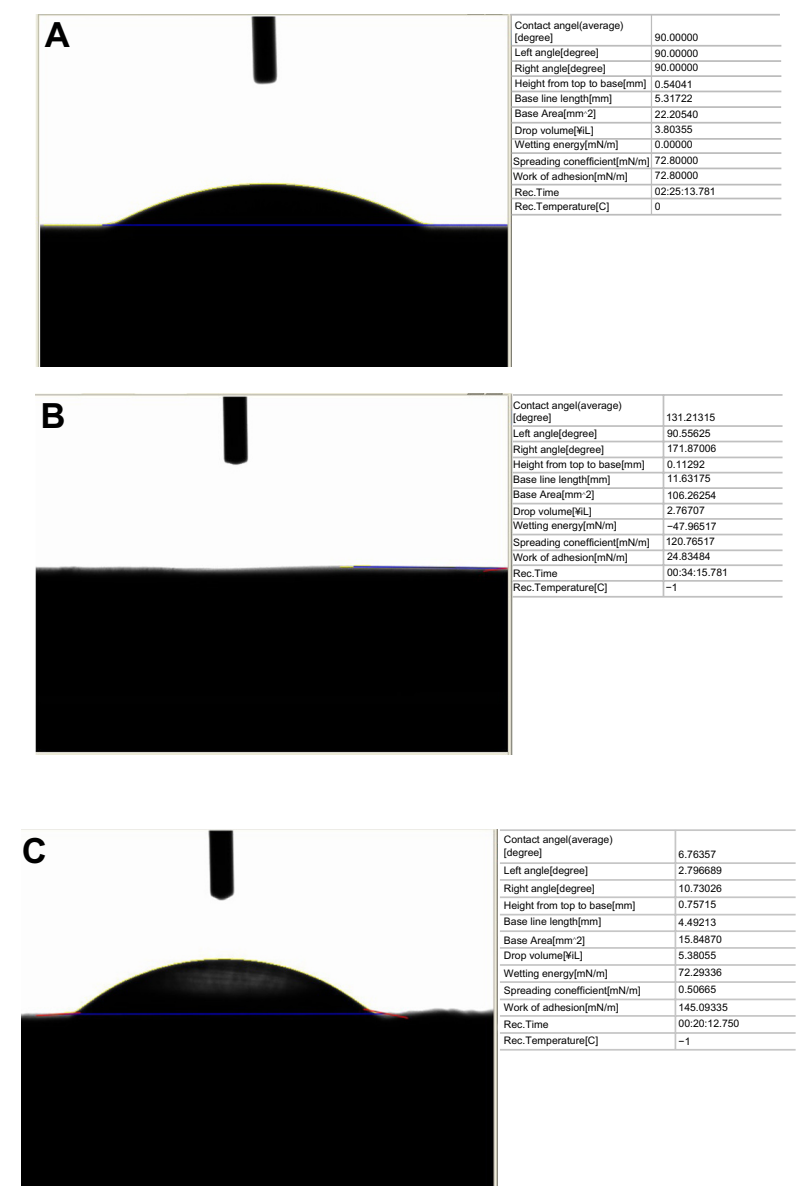

Figure 2 Contact angles on the samples of interest to the present study: (A) contact angle on plasma-sprayed hydroxyapatite on titanium $=90^{\circ}$; (B) contact angle on electrophoretic-deposited (EPD) hydroxyapatite on titanium = complete wetting; (C) contact angle on plain titanium $=6^{\circ}$. 


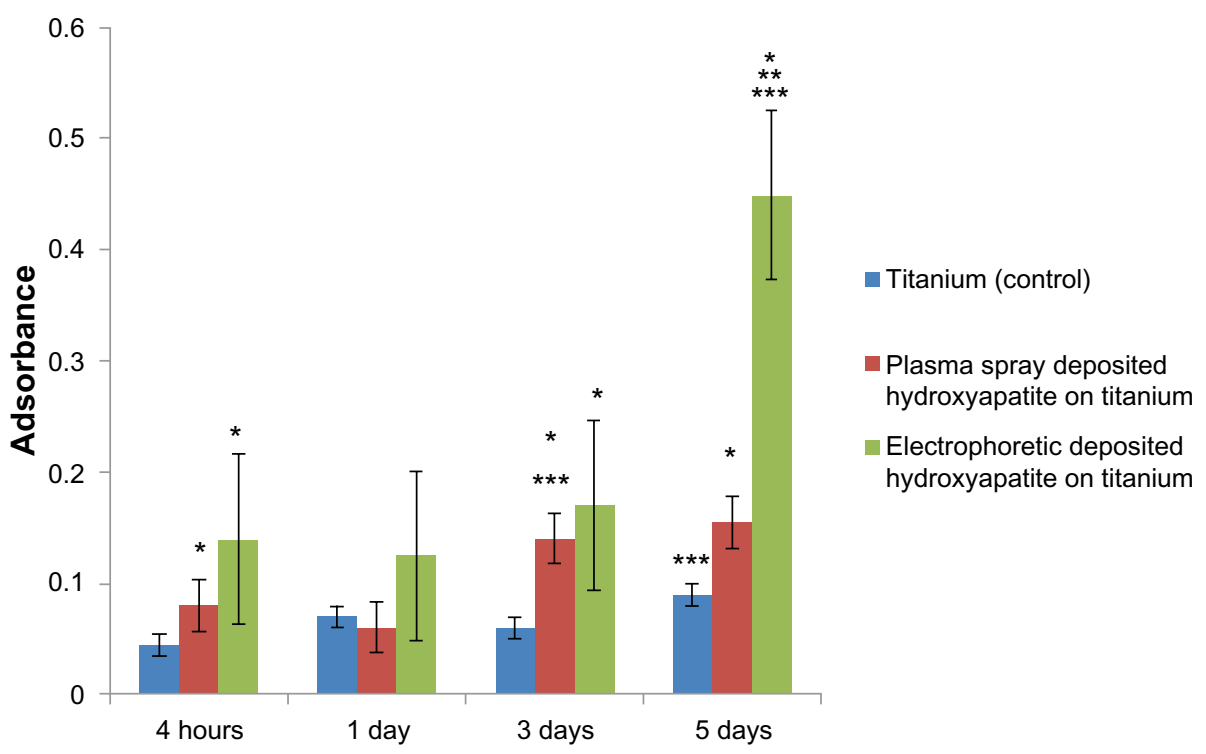

Figure 3 Increased osteoblast density on nanostructured electrophoretic-deposited hydroxyapatite on titanium (Ti) after 5 days of culture.

Notes: Data are expressed as mean \pm standard error of the mean; $\mathrm{N}=3 ; * \mathrm{P}<0.0 \mathrm{l}$ compared with $\mathrm{Ti}$ (control) at the same time period; $* * \mathrm{P}<0.0 \mathrm{l}$ compared with plasmasprayed-deposited hydroxyapatite on $\mathrm{Ti}$ at the same period; $* * * P<0.01$ compared with the previous time period on the same substrate. There was six and three times more osteoblast density on electrophoretic-deposited hydroxyapatite on $\mathrm{Ti}$ compared with $\mathrm{Ti}$ (control) and plasma-spray-deposited hydroxyapatite on $\mathrm{Ti}$, respectively.

for the present materials, previous studies have correlated the greater surface energy of nanostructured materials to the increased adsorption of hydrophilic proteins (such as fibronectin) to promote osteoblast density. ${ }^{31}$

For the present study, there were six and three times more osteoblasts on the electrophoretic-deposited HA on Ti compared with Ti (control) and plasma-spray-deposited HA on Ti after 5 days of culture, respectively (Figure 3 ). Micron-structured HA and plasma-spray deposition were used in the present study to emulate real clinical conditions. Since there is a strong correlation between increased osteoblast density and greater deposition of calcium by osteoblasts, ${ }^{31}$ these results imply greater formation of a mineralized matrix by osteoblasts when cultured on electrophoretic-deposited HA on Ti. Future studies will need to determine if extracellular matrix formation is enhanced by osteoblasts when cultured on electrophoretic-deposited HA on Ti.

Recent studies have also correlated greater surface hydrophilicity to the adsorption of hydrophilic proteins (such as mucin and lubricin) that can decrease bacteria attachment and growth. ${ }^{31}$ Indeed, in the present study, there were 2.9 and 31.7 times less bacteria on electrophoretic-deposited HA on Ti compared with $\mathrm{Ti}$ (control) and plasma-spray-deposited $\mathrm{HA}$ on Ti, respectively (Figure 4). Although the mechanism for the decreased bacteria functions on electrophoreticdeposited HA still needs to be determined, it is impressive that increasing nanoscale surface roughness without using antibiotics may be one of the reasons leading to such decreases in bacteria density. It is much easier using EPD to maintain HA nanoparticle size compared with high-heat coating processes like plasma-spray deposition. Although requiring further investigation, the increased bacteria on plasma-sprayed HA in this study may have been due to the greater hydrophobicity of the plasma-sprayed HA. In addition, since previous studies have measured decreased bacteria adhesion and growth on Ti surfaces with 20-80 nm surface features, ${ }^{18}$ future studies should determine the exact surface feature size that can optimize bacteria inhibition.

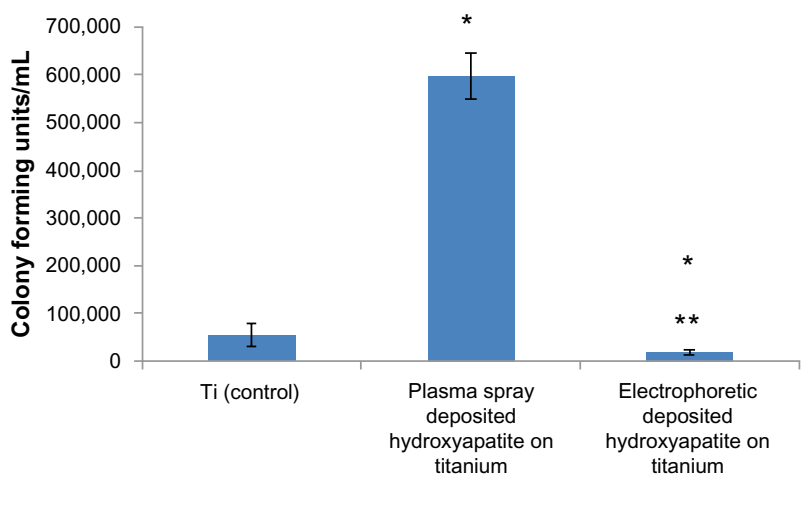

Figure 4 Significantly decreased bacteria density on nanostructured electrophoretic-deposited hydroxyapatite on titanium (Ti) after 18 hours of culture. Notes: Data are expressed as mean \pm standard error of the mean; $N=3 ; * P<0.01$ compared with $\mathrm{Ti}$ (control); $* * P<0.01$ compared with plasma-sprayed-deposited hydroxyapatite on $\mathrm{Ti}$. There was 2.9 and 31.7 times less bacteria on electrophoreticdeposited hydroxyapatite on $\mathrm{Ti}$ compared with $\mathrm{Ti}$ (control) and plasma-spraydeposited hydroxyapatite on $\mathrm{Ti}$, respectively. 


\section{Conclusion}

The present study demonstrated significantly greater nanoscale surface roughness when depositing HA electrophoretically compared with when using traditional plasma-spray deposition. Traditional plasma-spray deposition involves the use of high heat and results in micron-structured HA. The greater nanoscale roughness resulting from electrophoretically deposited HA led to greater osteoblast adhesion and impressively decreased bacteria colonization without the use of antibiotics or growth factors. As such, this study suggests that electrophoretic-deposited HA should be further studied with the aim of increasing osteoblast density and decreasing bacteria colonization.

\section{Acknowledgments}

We would like to thank Northeastern University for funding this research.

\section{Disclosure}

The authors declare no conflicts of interest in this work.

\section{References}

1. Feng B, Weng J, Yang BC, Qu SX, Zhang XD. Characterization of surface oxide films on titanium and adhesion of osteoblast. Biomaterials. 2003;24(25):4663-4670.

2. Centers for Disease Control and Prevention (CDC). FastStats: inpatient surgery [web page on the Internet]. Atlanta, GA: CDC; nd [last updated May 30, 2013]. Available from: http://www.cdc.gov/nchs/fastats/insurg. htm. Accessed November 19, 2013.

3. Bozic KJ, Kurtz SM, Lau E, et al. The epidemiology of revision total knee arthroplasty in the United States. Clin Orthop Relat Res. 2010;468(1):45-51.

4. Stanton T. Study points to savings with infection-screening program before TJR. American Academy of Orthopaedic Surgeons Now. 2010. Available from: http://www.aaos.org/news/aaosnow/mar10/clinical10. asp. Accessed November 19, 2013.

5. Kurtz SM, Ong KL, Lau E, Bozic KJ, Berry D, Parvizi J. Prosthetic joint infection risk after TKA in the Medicare population. Clin Orthop Relat Res. 2010;468(1):52-56.

6. Bozic KJ, Kurtz SM, Lau E, Ong K, Vail TP, Berry DJ. The epidemiology of revision total hip arthroplasty in the United States. J Bone Joint Surg Am. 2009;91(1):128-133.

7. Baquero F. Gram-positive resistance: challenge for the development of new antibiotics. J Antimicrob Chemother. 1997;39 Suppl A:1-6.

8. Campoccia D, Montanaro L, Arciola CR. The significance of infection related to orthopedic devices and issues of antibiotic resistance. Biomaterials. 2006;27(11):2331-2339.

9. Gottlieb T, Atkins BL, Shaw DR. Soft tissue, bone and joint infections. Med J Aust. 2002;176:609-615.

10. Manso M, Jiménez C, Morant C, Herrero P, Martínez-Duart JM. Electrodeposition of hydroxyapatite coatings in basic conditions. Biomaterials. 2000;21(17):1755-1761.

11. Yu WQ, Jiang XQ, Zhang FQ, Xu L. The effect of anatase TiO2 nanotube layers on MC3T3-E1 preosteoblast adhesion, proliferation, and differentiation. J Biomed Mater Res A. 2010;94(4):1012-1022.
12. Oh S, Brammer KS, Li YS, et al. Stem cell fate dictated solely by altered nanotube dimension. Proc Natl Acad Sci US A. 2009;106(7): 2130-2135.

13. Park J, Bauer S, von der Mark K, Schmuki P. Nanosize and vitality: TiO2 nanotube diameter directs cell fate. Nano Lett. 2007;7(6):1686-1691.

14. Puckett S. Select nanofabricated titanium materials for enhancing bone and skin growth of intraosseous transcutaneous amputation prostheses [doctoral dissertation]. Providence, RI: Brown University; 2010. Available from: https://repository.library.brown.edu/studio/item/ bdr:235/. Accessed November 19, 2013.

15. Puckett S, Pareta R, Webster TJ. Nano rough micron patterned titanium for directing osteoblast morphology and adhesion. Int J Nanomedicine. 2008;3(2):229-241.

16. Bjursten LM, Rasmusson L, Oh S, Smith GC, Brammer KS, Jin S. Titanium dioxide nanotubes enhance bone bonding in vivo. $J$ Biomed Mater Res A. 2010;92(3):1218-1224.

17. von Wilmowsky $\mathrm{C}$, Bauer S, Lutz R, et al. In vivo evaluation of anodic TiO2 nanotubes: an experimental study in the pig. J Biomed Mater Res B Appl Biomater. 2009;89(1):165-171.

18. Ercan B, Kummer KM, Tarquinio KM, Webster TJ. Decreased Staphylococcus aureus biofilm growth on anodized nanotubular titanium and the effect of electrical stimulation. Acta Biomater. 2011;7(7): 3003-3012.

19. Ercan B, Taylor E, Alpaslan E, Webster TJ. Diameter of titanium nanotubes influences anti-bacterial efficacy. Nanotechnology. 2011;22(29):295102.

20. Puckett SD, Taylor E, Raimondo T, Webster TJ. The relationship between the nanostructure of titanium surfaces and bacterial attachment. Biomaterials. 2010;31(4):706-713.

21. Alpaslan E, Ercan B, Webster TJ. Anodized $20 \mathrm{~nm}$ diameter nanotubular titanium for improved bladder stent applications. Int $J$ Nanomedicine. 2011;6:219-225.

22. Ercan B. Anodized nanotubular titanium as an orthopedic implant and the effect of electrical stimulation [doctoral dissertation]. Providence, RI: Brown University; 2011. Available from: https://repository.library. brown.edu/studio/item/bdr:11208/. Accessed November 19, 2013.

23. Puckett SD, Lee PP, Ciombor DM, Aaron RK, Webster TJ. Nanotextured titanium surfaces for enhancing skin growth on transcutaneous osseointegrated devices. Acta Biomater. 2010;6(6):2352-2362.

24. Rajyalakshmi A, Ercan B, Balasubramanian K, Webster TJ. Reduced adhesion of macrophages on anodized titanium with select nanotube surface features. Int J Nanomedicine. 2011;6:1765-1771.

25. Corni I, Ryan MP, Boccaccini AR. Electrophoretic deposition: from traditional ceramics to nanotechnology. J Eur Ceram Soc. 2008;28(7): 1353-1367.

26. Boccaccini AR, Keim S, Ma R, Li Y, Zhitomirsky I. Electrophoretic deposition of biomaterials. J R Soc Interface. 2010;7 Suppl 5: S581-S613.

27. Boccaccini AR, Zhitomirsky I. Application of electrophoretic and electrolytic deposition techniques in ceramic processing. Solid State and Materials Science. 2002;6(3):251-260.

28. Mohan L, Durgalakshmi D, Geetha M, Sankara Narayanan TS, Asokamani R. Electrophoretic deposition of nanocomposite $\left(\mathrm{HAp}+\mathrm{TiO}_{2}\right)$ on titanium alloy for biomedical applications. Ceramics International. 2012;38:3435-3443.

29. Zhang Z, Dunn MF, Xiao TD, Tomsia AP, Saiz E. Nanostructured hydroxyapatite coatings for improved adhesion and corrosion resistance for medical implants. Mater Res Soc Symp Proc. 2002;703:291-296.

30. Zhitomirsky I, Gal-Or L. Electrophoretic deposition of hydroxyapatite. J Mater Sci Mater Med. 1997;8(4):213-219.

31. Sato M, Slamovich EB, Webster TJ. Enhanced osteoblast adhesion on hydrothermally treated hydroxyapatite/titania/poly(lactide-co-glycolide) sol-gel titanium coatings. Biomaterials. 2005;26(12):1349-1357. 
International Journal of Nanomedicine

Dovepress

\section{Publish your work in this journal}

The International Journal of Nanomedicine is an international, peerreviewed journal focusing on the application of nanotechnology in diagnostics, therapeutics, and drug delivery systems throughou the biomedical field. This journal is indexed on PubMed Central, MedLine, CAS, SciSearch ${ }^{\circledR}$, Current Contents ${ }^{\circledR} /$ Clinical Medicine,
Journal Citation Reports/Science Edition, EMBase, Scopus and the Elsevier Bibliographic databases. The manuscript management system is completely online and includes a very quick and fair peer-review system, which is all easy to use. Visit http://www.dovepress.com/ testimonials.php to read real quotes from published authors.

Submit your manuscript here: http://www.dovepress.com/international-journal-of-nanomedicine-journal 